\title{
Green Nanotechnology from Plant Extracts: Synthesis and Characterization of Gold Nanoparticles
}

\author{
Adriana Napoleão Geraldes ${ }^{1}$, Andressa Alves da Silva1 ${ }^{1}$, Jessica Leal ${ }^{1}$, \\ Gethzemani Mayeli Estrada-Villegas', Nilton Lincopan' ${ }^{2}$, Kattesh V. Katti ${ }^{3}$, \\ Ademar Benévolo Lugão ${ }^{*}$ \\ ${ }^{1}$ Centro de Química e Meio Ambiente, Instituto de Pesquisas Energéticas e Nucleares-Comissão Nacional de \\ Energia Nuclear (IPEN-CNEN), São Paulo, Brazil \\ ${ }^{2}$ Laboratório de Resistência Bacteriana \& Alternativas Terapêuticas, Instituto de Ciências Biomédicas, \\ São Paulo, Brazil \\ ${ }^{3}$ Department of Radiology, Physics, Bio-Medical Sciences, Nuclear Science and Engineering Institute, University \\ of Missouri-Columbia, Columbia, USA \\ Email: "ablugao@ipen.br
}

Received 22 July 2016; accepted 16 August 2016; published 19 August 2016

Copyright (C) 2016 by authors and Scientific Research Publishing Inc.

This work is licensed under the Creative Commons Attribution International License (CC BY). http://creativecommons.org/licenses/by/4.0/

(c) (i) Open Access

\section{Abstract}

The advantage of using plants in nanoparticles synthesis is that they are easily available, safe to handle and possess a broad variability of metabolites such as antioxidants, nucleotides and vitamins. The aim of this study was to investigate the effects of Green and Zimbro tea and also Green coconut water as a reducing and stabilizer agent in gold nanoparticle synthesis. The gold nanoparticles were characterized by UV-Vis absorption spectroscopy, X-ray diffraction (XRD), Dynamic light scattering (DLS) and Transmission electron microscopy (TEM) analysis. Their physical stability was determined using a UV-Vis spectrophotometer over several days during storage at room temperature. We observed that green chemical process to obtain gold nanoparticles did not require any external chemicals reagent for stabilization of nanoparticulate. Absorption measurements indicated that the plasmon resonance wavelength appears around $530 \mathrm{~nm}$. X-ray diffractograms of gold nanoparticles evidenced the presence of Au-rich ( $\mathrm{fcc}$ ) phases. TEM analysis showed a homogeneous dispersion of nanoparticles and some agglomerates. Differences in size and shape of the nanoparticles were observed. Zeta potential of AuNPs synthetized in presence of Green tea was $\mathbf{- 3 3} \mathbf{m V}$ indicating stability of the synthesized nanoparticles.

\section{Keywords}

Green Nanotechnology, Gold Nanoparticles, Camellia sinensis, Juniperus communis,

${ }^{*}$ Corresponding author.

How to cite this paper: Geraldes, A.N., da Silva, A.A., Leal, J., Estrada-Villegas, G.M., Lincopan, N., Katti, K.V. and Lugão, A.B. (2016) Green Nanotechnology from Plant Extracts: Synthesis and Characterization of Gold Nanoparticles. Advances in Nanoparticles, 5, 176-185. http://dx.doi.org/10.4236/anp.2016.53019 


\section{Green Coconut Water}

\section{Introduction}

Nanotechnology is one of the fastest growing areas of Science and technology. The synthesis of metal nanoparticles is an active area of research in the field of nanotechnology with an exponential progress in biomedical applications including imaging, diagnostics, drug delivery and therapeutics using metal nanoparticles [1] [2].

Several chemical and physical methods have been used for synthesis of nanoparticles. However, a number of methods present disadvantages including use of toxic solvents, high-energy consumption, hazardous products etc. Therefore, there is an essential need to develop environment friendly methods for synthesis of metal nanoparticles. The development of eco-friendly technologies in material synthesis is of considerable importance to expand their biological applications. Nowadays, varieties of green nanoparticles with well-defined chemical composition, size, and morphology have been synthesized by different methods and their applications in many innovative technological areas have been explored [3]-[6].

Due to their unique optical, electrical and catalytic properties, gold nanoparticles (AuNPs) have been used in many areas of life, mainly in medicine, electronics and technologies of manufacturing modern materials [4]-[10]. AuNPs have been highly used as agents in biomedical detection and contrasting image due to its properties that match: biocompatibility, bioconjugation and optical properties. Their small size, high surface area and stability at high temperatures make them perfect tool in medical diagnostics, photodynamic therapy as well as in the active transport of drugs, especially for cancer treatment [11], minimizing the damage cell during optical staining or biomarker tagging even as during the delivery of biomolecules/drugs to the target cell/tissue/organ [12]. Gold nanoparticles have been employed in radiotherapy, in two modes: to increase local dose deposition in tissue during radiotherapy or as a local emitter of gamma and beta rays. The radioactive properties of gold include: ${ }^{198} \mathrm{Au}\left(\beta_{\max }=0.96 \mathrm{MeV} ; t_{1 / 2}=2.7\right.$ days $)$ and ${ }^{199} \mathrm{Au}\left(\beta_{\max }=0.46 \mathrm{MeV} ; t_{1 / 2}=3.14\right.$ days $)$, making it a strong candidate to therapeutic radio applications [13]-[15]. Furthermore, both isotopes have gamma emission that can be used in pharmacokinetic and dosimetric studies.

AuNPs are generally unstable because of their high surface and a suitable stabilizer should be added to prevent aggregation [11].

The renewable nature of plant extracts, eco-friendly aqueous medium and mild reaction conditions make the method advantageous over other hazardous methods. In the last years, different kind plants extract and their products have received attention due to its low cost, energy-efficient and nontoxic behavior in approach for synthesis of metal nanoparticles [4]. Thus, the focus has turned toward Green nanotechnology. The green synthesis of metal nanoparticles should involve three main steps based on green chemistry perspectives, namely 1) the selection of a biocompatible and nontoxic solvent medium, 2) the selection of environmentally favorable reducing agents, and 3) the selection of nontoxic substances for stabilization of the nanoparticles. Many works have been done using plant extracts to promote the reduction of metal nanoparticles due to the presence of some phytochemicals. They have been extensively used in the treatment of various diseases including human cancer. That substances serve as a dual role: effective reducing agents to reduce gold and also as stabilizers to provide a coating on the gold nanoparticles in a single step [4] [12]-[18]. The main phytochemicals responsible have been identified as terpenoids, flavones, ketones, aldehydes, amides and carboxylic acids through Fourier Transform Infra-Red (FT-IR) spectroscopy studies. The main water-soluble phytochemicals are flavones, organic acids and quinones, which are responsible for immediate reduction [4] [7].

The growing evidence towards the health benefits of Camellia sinensis (Green tea) has resulted in extensive studies to understanding the curing power of tea [11]. A well-accepted scientific consensus emanating from several scientific investigations is that tea contains high levels of antioxidant polyphenols, including flavonoids, and catechins, all of which scavenge the dangerous free radicals in the body and thus, prevent the progress of various diseases [11] [19]-[23]. The tea-generated gold nanoparticles (T-AuNPs), have demonstrated remarkable in vitro stability in various buffers including saline, histidine and cysteine solutions. Nune et al. studied T-AuNPs with several phytochemical coatings. The results have shown significant affinity toward prostate (PC-3) and breast (MCF-7) cancer cells. Moreover, results on the cellular internalization of T-AuNPs through endocytosis into the PC-3 and MCF-7 cells are presented. The generation of T-AuNPs follows all principles of green chemistry and 
T-AuNPs have been found to be nontoxic as assessed through MTT assays. Natural chemicals, other than gold salts, were used in this truly biogenic, green nanotechnological process thus paving the way for excellent opportunities for their application in molecular imaging and therapy [11].

Nestor et al. employing Green tea extract as reducing and stabilizing agent for production of gold and silver nanostructures in aqueous solution at ambient conditions. Colloidal systems of silver and gold nanoparticles exhibit highly efficient single photon-induced luminescence. This optical response can be manipulated by changing concentrations of metal ions and the quantity of reducing agent, which plays a crucial role in formation, growth and luminescence response of these noble-metal nanostructures [24].

On the other hand, Juniperus communis (Zimbro tea) has been used in various diseases including antidiabetic effect, treatment of kidney infections, as diuretic, stomachic, treatment of rheumatism, cardiac and skin diseases. There are some studies about the constituents of the fruit of J. communis where polyphenols, polyphenol esters, and monoterpenes hydrocarbons [25] [26] were isolated.

As an alternative, the coconut shell extract have been reported as antibacterial, and antiviral [27] and anti-inflammatory [28], among others properties. Moreover, a very mild and environment-friendly method for the synthesis of AuNPs from Green coconut shell (mesocarp) extract without any additional capping or stabilizing agents was too reported [29]. Paul et al. studied the shell extract of green coconut (Cocos nucifera Linn) for the synthesis of gold nanoparticles at room temperature under very mild condition without any extra stabilizing or capping agents. The size of the synthesized gold nanoparticles could be controlled by varying the concentration of the shell extract [29]. The coconut water (C. nucifera) as the reducing agent was employed for Elumai et al. on the synthesis of silver nanoparticles (Ag-NPs). The synthesized Ag-NPs were predominately polydispersed. Fourier Transform Infra-Red (FT-IR) spectroscopy analysis showed that the synthesized nanoparticles were capped with bimolecular compounds, which are responsible for the reduction of silver ions [30].

In our laboratory, there is a high interest in the study of gold nanoparticles synthesis for many application including cancer treating and/or cosmetology. In this context, the aim of this study was investigate the effect of different plants as reducing and stabilizer agent in gold nanoparticle formulation, namely: Green tea, Zimbro tea and Green coconut water. In the other words, we are interested in an environment-friendly method for the synthesis of AuNPs from plants extract without any additional reducing or stabilizing chemical agents. The stabilized colloidal AuNPs was characterized by UV-Vis absorption spectroscopy, energy dispersive X-ray spectroscopy (XRD), Dynamic light scattering (DLS), and Transmission electron microscopy (TEM) analysis. Their physical stability was determined using a UV-Vis spectrophotometer over several days during storage at room temperature.

\section{Materials and Methods}

\subsection{Solution Preparation}

All chemicals and plant extracts precursors used in the synthesis of gold nanoparticles (AuNPs) were purchased from suppliers: $\mathrm{HAuCl}_{4} \cdot 3 \mathrm{H}_{2} \mathrm{O}$ (Fluka), Camellia sinensis, J. communis and Green coconut water were obtained from a local market. For Camellia (Green tea) extract, $1 \mathrm{~g}$ of leafs was placed in $50 \mathrm{~mL}$ of boiling water and magnetic stirrer for 30 minutes. For $J$. communis (Zimbro tea) extract, $1 \mathrm{~g}$ of fruit was macerated, placed in 50 $\mathrm{mL}$ of boiling water and magnetic stirrer for 60 minutes.

To $10 \mathrm{~mL}$ vials was added $0.1 \mathrm{~mL}$ of $0.1 \mathrm{~mol} \cdot \mathrm{L}^{-1} \mathrm{HAuCl}_{4}$ solution (in DI water) $9.9 \mathrm{~mL}$ of Green tea, Zimbro tea solution or Green coconut water (in triplicate). The reaction was stirred continuously at $25^{\circ} \mathrm{C}$. The color of the mixture started in pale yellow and become purple-red after 15, 90 and 30 minutes for Green tea, Zimbro tea solution and Green coconut water respectively, indicating the formation of gold nanoparticles. The reaction mixture was stirred for an additional 20 minutes.

The gold nanoparticles formed were characterized by UV-Vis absorption spectroscopy, Energy dispersive X-ray spectroscopy (XRD), Dynamic light scattering (DLS) and Transmission electron microscopy (TEM) analysis. Their physical stability was determined using a UV-Vis spectrophotometer over several days during storage at room temperature.

\subsection{Characterization}

\subsubsection{UV-Vis Spectroscopy}

The solutions were characterized by absorption spectroscopy in the UV-Vis Spectrophotometer SpectraMax I3, 
Soft Max Pro ${ }^{\circledR}$ 6.4 Microplate Analysis Software to confirm the peak surface plasmon resonance of the gold nanoparticles at $\lambda=535 \mathrm{~nm}$, approximately. The spectra were recorded at first day and after 1, 2 weeks and finally after 1 month. All samples were diluted with water in each measure to guarantee that the maximum absorbance below 1.5 .

\subsubsection{X-Ray Diffraction (XRD) Analysis}

X-ray diffraction (XRD) analyses were carried out with a Miniflex II model Rigaku diffractometer using a $\mathrm{Cu}$ $K \alpha$ source $(\lambda=1.54056 \AA)$. The diffractograms were recorded at $2 \theta$ in the range $20^{\circ}-90^{\circ}$ with step size of $0.05^{\circ}$ and scan time of $2 \mathrm{~s}$ per step.

\subsubsection{Dynamic Light Scattering (DLS) Analysis}

Dynamic light scattering (DLS) was carried out using Zeta Plus-Zeta Potential Analyzer (Brookhaven Instruments Corporation, Holtsville, NY), which was equipped with a $677 \mathrm{~nm}$ laser and dynamic light-scattering (PCS) at $90^{\circ}$ for particle sizing. The particle size (multimodal size distribution) was determined by measuring the angles at which an incident light beam is scattered as a function of Brownian motion of the colloidal gold particles. $1 \mathrm{~mL}$ of each sample was filtered in CHROMAFIL ${ }^{\circledR}$ Xtra PVDF-20/25, until measurement.

\subsubsection{Transmission Electron Microscopy (TEM) Analysis}

Transmission electron microscopy (TEM) was carried out using a JEOL JEM-2100 electron microscope, operated at $200 \mathrm{kV}$. The particle distribution histogram was determined by measuring the particles by Lince program.

\section{Results and Discussion}

UV-vis spectroscopy is one of the most important techniques to determine and evaluate the formation and stability of metal nanoparticles in aqueous solution. Gold nanoparticles produced by Green synthesis did not require any external chemicals agents for the reduction and stabilization of the nanoparticle. Phytochemicals substances presents in tea or coconut water are presumably responsible for the creation of coating on gold nanoparticles and thus, rendering the nanoparticles stable against agglomeration [4]. Figure 1 shows the UV-Vis spectra of gold nanoparticle formation at constant concentration of $\mathrm{HAuCl}_{4}\left(1 \mathrm{mmol} \cdot \mathrm{L}^{-1}\right)$ for Green, Zimbro tea and Green coconut water solutions. The absorbance was observed around $\lambda_{\max }=530-540 \mathrm{~nm}$ for all solutions, indicating the formation of AuNPs [4] due to the excitation of the surface plasmon vibrations in the AuNPs, but is possible to find the plasmon band of AuNPs in ranges from 510 to $560 \mathrm{~nm}$ [31] [32]. It is evident from Figure 1 that in Green and Zimbro tea AuNPs solution was not observed any displacement in $\lambda_{\max }$ (540 or $530 \mathrm{~nm}$ respectively), meanwhile had a displacement in around $20 \mathrm{~nm}$ over time for Green coconut water AuNPs in $\lambda_{\max }$, suggesting that Green and Zimbro tea AuNPs were more stable than Green coconut water AuNPs. These results showed that Green coconut water is not efficient enough to stabilizing the gold nanoparticles for longs periods due to the AuNPs agglomeration were observed after 2 weeks. In the other samples, the agglomeration of AuNPs was not observed after almost 1 month.

The XRD diffractogram of gold nanoparticles reduced and stabilized with Green tea displayed in Figure 2, show five diffraction peaks at about $2 \theta=38^{\circ}, 45^{\circ}, 65^{\circ}, 78^{\circ}$ and $82^{\circ}$, attributed to the (111), (200), (220), (311) and (222) planes, respectively, which are characteristic of the fcc structure of Au [8] [33]. The AuNPs reduced and stabilized with Zimbro tea and Green coconut water were not characterized by XRD technique.

Particle size and size distribution are the most important characteristics of nanoparticle systems. They determine the in vivo distribution, biological fate, toxicity and the targeting ability of nanoparticle systems. In addition, they can also influence the drug loading, drug release and stability of nanoparticles. Many studies have demonstrated that nanoparticles of sub-micron size have a number of advantages over microparticles as a drug delivery system. Generally, nanoparticles have relatively higher intracellular uptake compared to microparticles and available to a wider range of biological targets due to their small size and relative mobility [34].

In Figure 3 the dynamic light scattering (DLS) histogram of multimodal size distribution and zeta sizer corresponding to the AuNPs in Green, Zimbro tea and Green coconut water solutions. The DLS method was employed to determine the size of AuNPs coated with all phytochemicals present on tea. Different particle size distribution curves were observed using three different green stabilizers. The Size distribution and zeta sizer are 

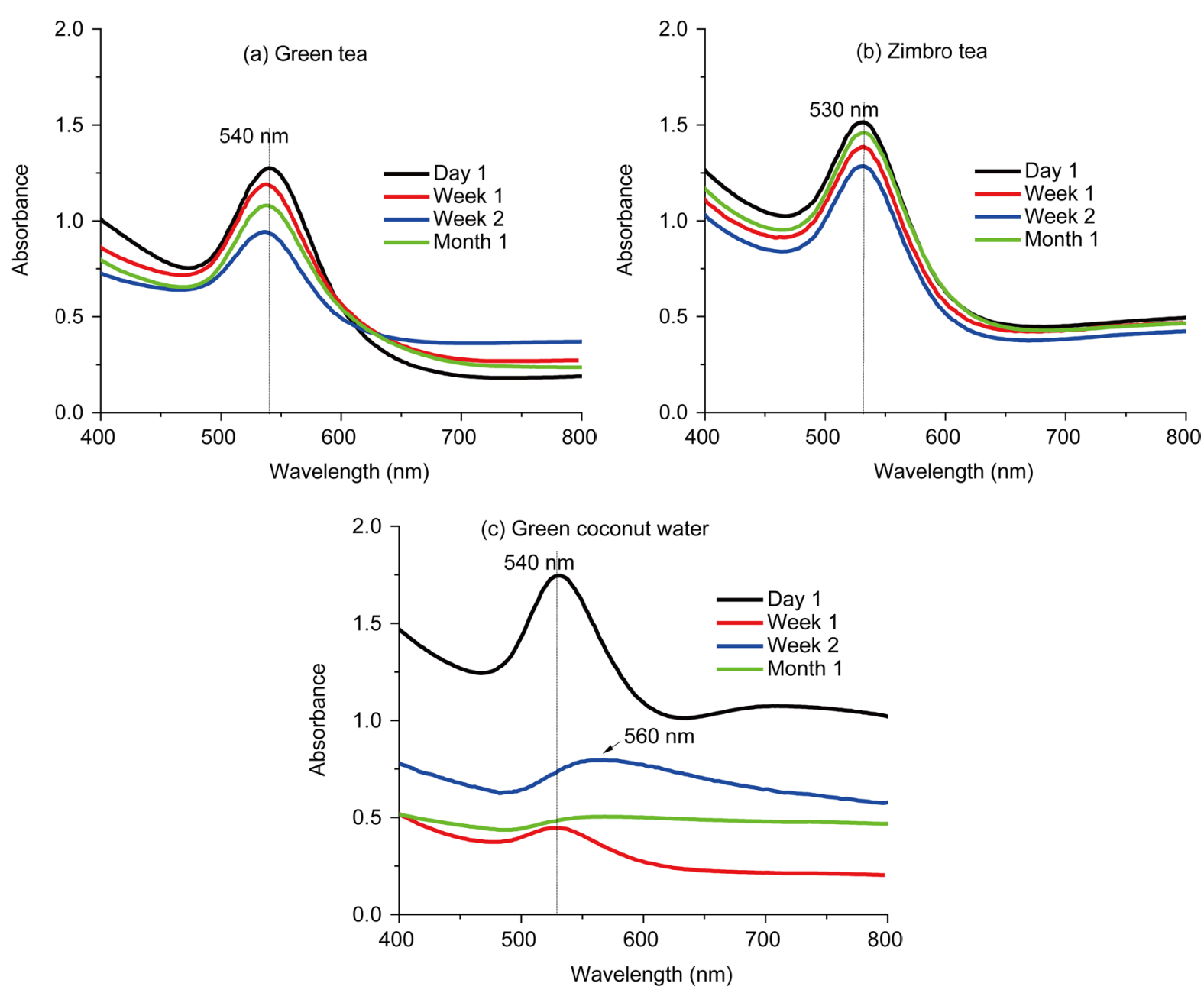

Figure 1. UV-Vis spectra of different gold nanoparticles solutions reduced and stabilized with (a) Green tea, (b) Zimbro tea and (c) Green coconut water at $25^{\circ} \mathrm{C}$.

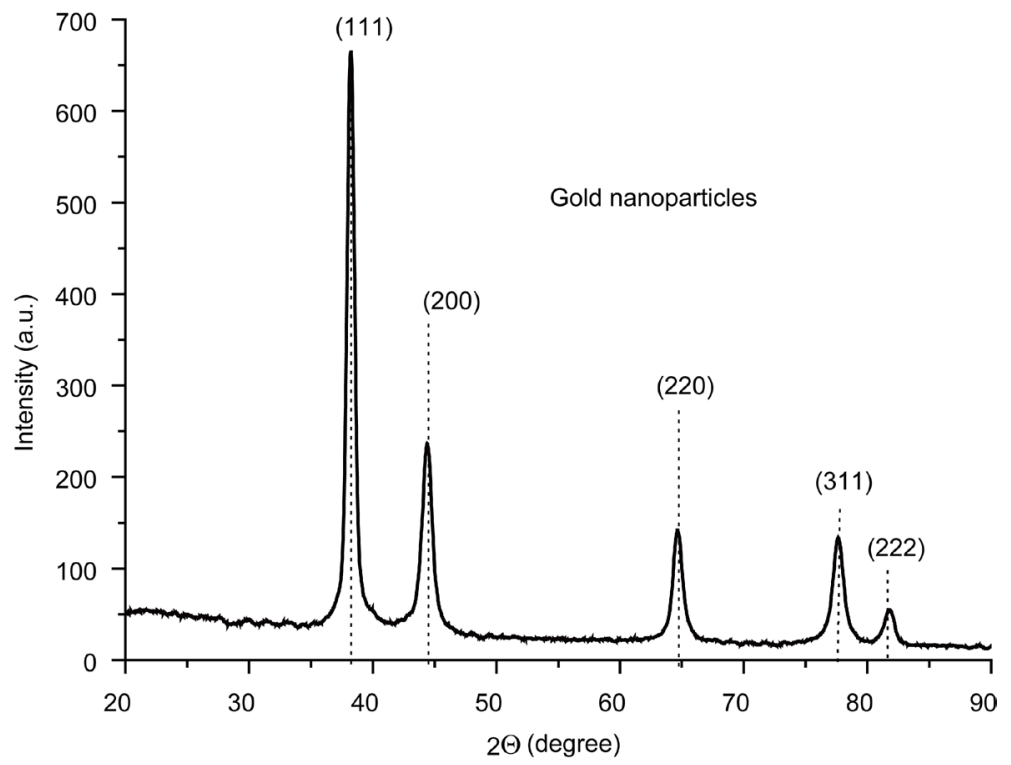

Figure 2. X-ray diffractograms of Gold nanoparticles reduced and stabilized with Green tea. 
shown in the Table 1. Difference in size of AuNPs suggesting that AuNPs are coated with phytochemicals with low and high molecular weight [1].

The zeta potential of a nanoparticle is commonly used to characterize the surface charge property of nanoparticles. It reflects the electrical potential of particles and is influenced by the composition of the particle and the medium in which it is dispersed. Nanoparticles with a zeta potential above ( \pm ) $30 \mathrm{mV}$ have been shown to be stable in suspension, as the surface charge prevents aggregation of the particles [1] [35]. In our results only the zeta potential of AuNPs synthesized with green tea was above $30 \mathrm{mV}(-33 \mathrm{mV})$ indicating the stability of the AuNPs.

TEM micrographs of AuNPs, shows the shape, particle size and their histograms distribution (Figure 4). In Figure 4(a), small and larger nanoparticles were formed, showing agglomerates of hexagonal shape and particle size between 40 - $70 \mathrm{~nm}$. In Figure 4(b), the agglomeration of AuNPs was lower than the last one and the particle
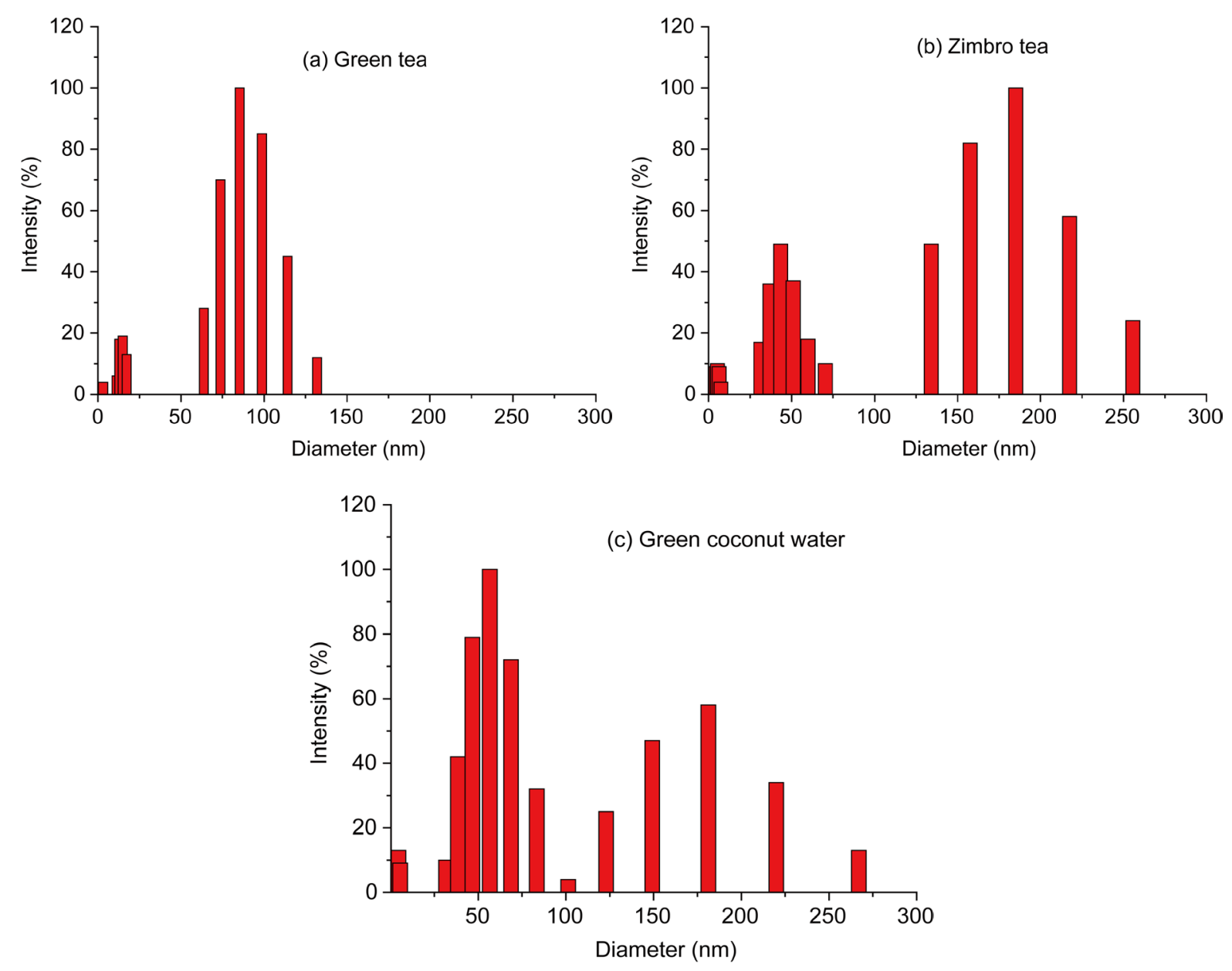

Figure 3. Histogram of multimodal size distribution corresponding different gold nanoparticles solutions reduced and stabilized with (a) Green tea, (b) Zimbro tea and (c) Green coconut water.

Table 1. Size distribution and zeta potential obtained by DLS of different gold nanoparticles solutions reduced and stabilized with Green tea, Zimbro tea and Green coconut water.

\begin{tabular}{ccccc}
\hline Sample & \multicolumn{3}{c}{ Size distribution $(\mathbf{n m})$} & Zeta potential $(\mathbf{m V})$ \\
\hline Green tea & 14 & 84 & - & -33 \\
Zimbro tea & 5 & 43 & 184 & -16 \\
Coconut water & 4 & 56 & 181 & -5.8 \\
\hline
\end{tabular}



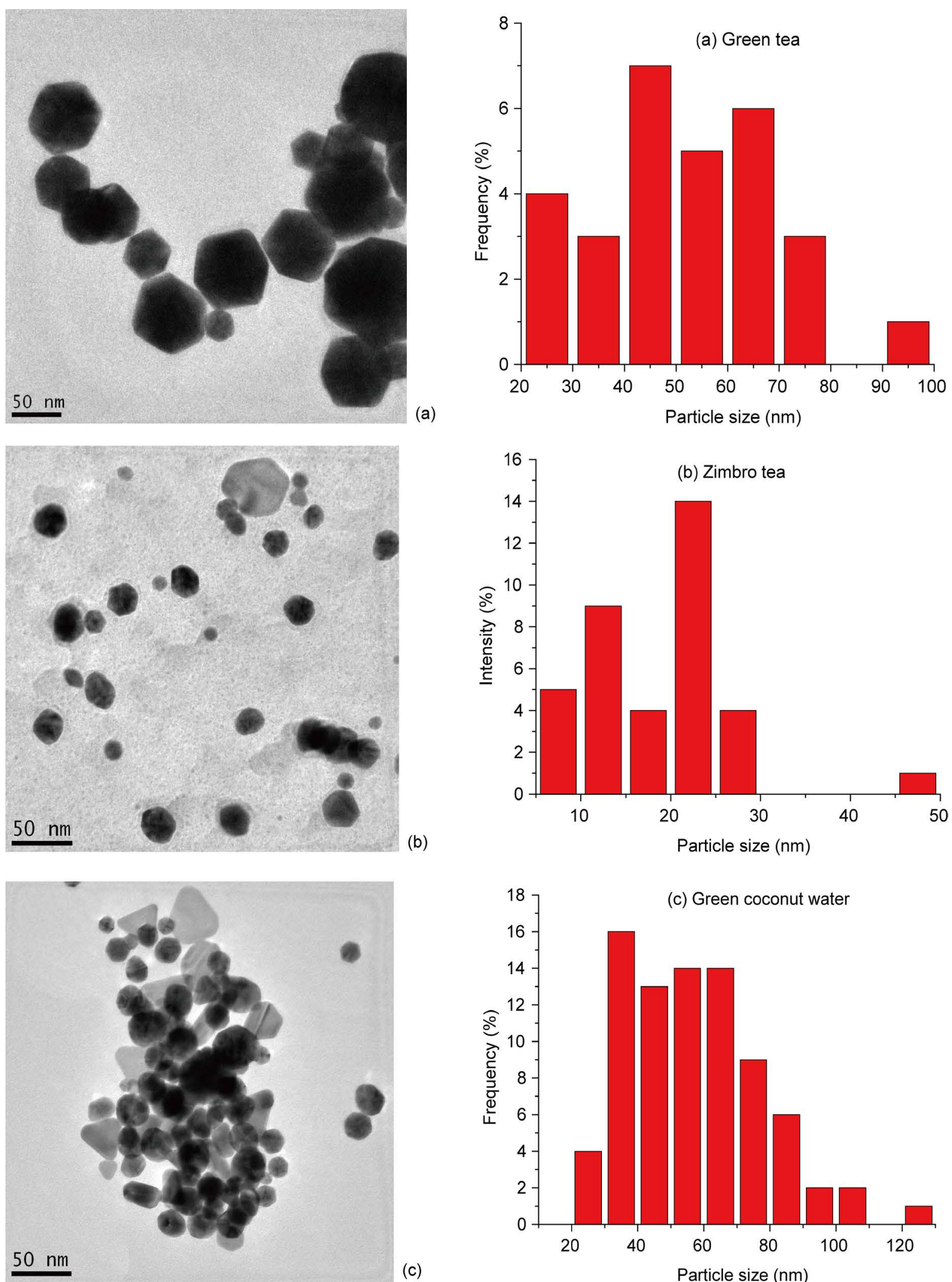

(b)

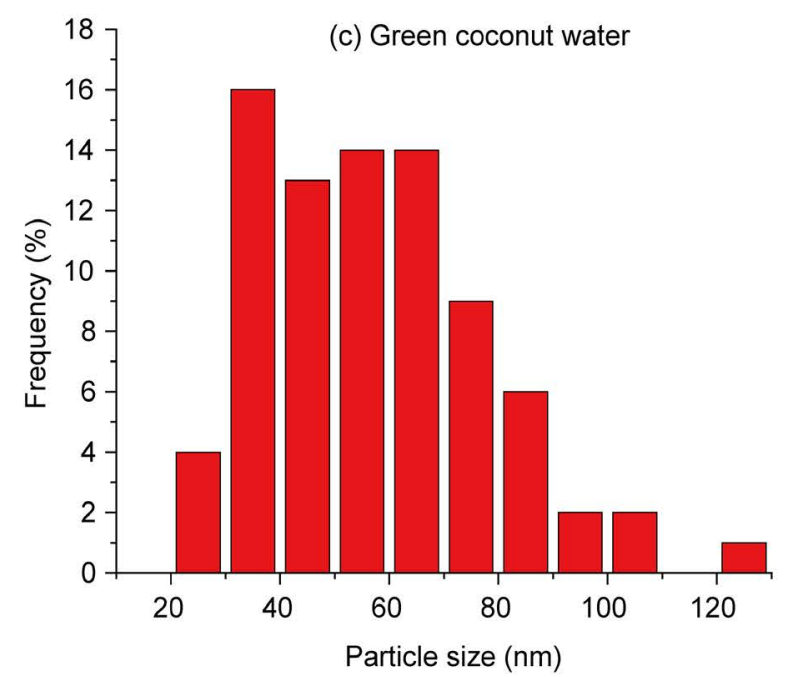

Figure 4. TEM micrographs and particle size distribution histograms of AuNPs reduced and stabilized with (a) Green tea, (b) Zimbro tea and (c) Green coconut water. 
size was between 20 - $30 \mathrm{~nm}$ showing circular and hexagonal shapes. Circular, triangular, hexagonal and rodshaped nanoparticles were observed in Figure 4(c) showing particle sizes were between $30-70 \mathrm{~nm}$. The results suggest that smaller particle size synthesize with Zimbro tea is due to it promote the presence of more nucleation site for $\mathrm{AuCl}_{4}$-complexation. It is also possible that Zimbro tea components have effectively protection for synthesized nanoparticles thus preventing their aggregation. Whereas for Green tea probably less number of nucleation sites would be present more reduction has taken place at nuclei that leading to formation of bigger particle. This observation is in agreement to Mata et al. who prepared gold nanoparticles using aqueous Plumeria alba flower extract (PAFE). The use of $1 \%$ and 5\% concentrations of PAFE resulted in two different sizes of P. alba gold nanoparticles, PAGNPs1 and PAGNPs2. The average particle diameters of PAGNPs1 and PAG-NPs2 are found to be 36.05 and $20.65 \mathrm{~nm}$, respectively. A possible explanation for the formation of smaller particles in PAGNPs2 could be the presence of the increased number of nucleation sites for $\mathrm{AuCl}_{4}$-complexation with the increasing concentration of the PAFE. Whereas in PAGNPs1, less nucleation sites were present this may lead to more reduction at one nucleation and formation of bigger particles [5]. Various nanoparticles shapes were too observed by Philip using the leaf extract of Hibiscus rosa sinensis. The size and shape of Au nanoparticles were modulated varying the ratio of metal salt and extract in the reaction medium [36]. Paul et al. [29] found AuNPs of spherical, triangular, tetragonal, pentagonal and hexagonal shapes using shell coconut extract. The average size of the AuNPs were 20 - $9.5 \mathrm{~nm}$ the extent to which increasing the coconut extract concentration. At higher concentration of the shell extract, the polyphenolic compounds, quinones and other chelating phytochemicals present in the shell extract can effectively stabilize the smaller sized AuNPs.

The difference in size of particles observed by DLS when compared to TEM is the fact that the measured size also includes the bio-organic compounds enveloping the core of the AuNPs [11].

Gold nanoparticles generated through that process presents agglomerate suggesting that the combination of thearubigins, theaflavins, catechins and various phytochemicals present in green reducing and stabilizer agent studied in this paper serve as excellent stabilizers on nanoparticles and thus, optionally provide shielding from agglomeration [4].

\section{Conclusion}

In this contribution, gold nanoparticles of different size and shape were synthesized using Green and Zimbro tea and Green coconut water as a reducing and stabilizer agent without adding of different physical and chemical steps. From the point of view of nanotechnology, this was a significant advancement to synthesize gold nanoparticles by economically procedure. The reported syntheses were not only simple and cost-effective but also capable of providing monodisperse, functional gold nanoparticles. It was possible because green reducing and stabilizer agents perform an effectively protection and prevent their aggregation. The AuNPs were confirmed by UV-vis due to the presence of a peak around $535 \mathrm{~nm}$ concerning the surface plasmon resonance characteristic of AuNPs. These nanoparticles were stable in water for at least one month, for Green and Zimbro tea, which can be attributed to surface binding of various phytochemicals substances present in tea. Overall, the results suggested that Green tea provided the formation of more stable nanoparticles. These results showed a wide range of particle sizes and shapes. Finally the synthesis of gold nanoparticles was carried out at room temperature, atmospheric pressure and were made in water (universal solvent), indicating a green process that presents a reliable and economic method.

\section{Acknowledgements}

The authors thank CNPq Project number (150135/2015-7) and Nildemar Ferreira from CCTM IPEN/CNEN-SP for TEM measurements.

\section{References}

[1] Mukherjee, S., Sushma, V., Patra, S., Barui, A.K., Bhadra, M.P., Sreedhar, B. and Patra, C.R. (2012) Green Chemistry Approach for the Synthesis and Stabilization of Biocompatible Gold Nanoparticles and Their Potential Applications in Câncer Therapy. Nanotechnology, 23, 455103-455116. http://dx.doi.org/10.1088/0957-4484/23/45/455103

[2] Rastogi, L. and Arunachalam, J. (2013) Green Synthesis Route for the Size Controlled Synthesis of Biocompatible Gold Nanoparticles Using Aqueous Extract of Garlic (Allium sativum). Advanced Matterials Letters, 4, 548-555. 
[3] Yu, J., Xu, D., Guan, H.N., Wang, C., Huang, L.K. and Chi, D.F. (2016) Facile One-Step Green Synthesis of Gold Nanoparticles Using Citrus maxima Aqueous Extracts and Its Catalytic Activity. Materials Letters, 166, 110-112. http://dx.doi.org/10.1016/j.matlet.2015.12.031

[4] Nath, D. and Banerjee, P. (2013) Green Nanotechnology_A New Hope for Medical Biology. Environmental Toxicology and Pharmacology, 36, 997-1014. http://dx.doi.org/10.1016/j.etap.2013.09.002

[5] Mata, R., Bhaskaran, A. and Sadras, S.R. (2016) Green-Synthesized Gold Nanoparticles from Plumeria alba Flower Extract to Augment Catalytic Degradation of Organic Dyes and Inhibit Bacterial Growth. Particuology, 24, 78-86. http://dx.doi.org/10.1016/j.partic.2014.12.014

[6] Azandehi, P.K. and Moghaddam, J. (2015) Green Synthesis, Characterization and Physiological Stability of Gold Nanoparticles from Stachys lavandulifolia Vahl Extract. Particuology, 19, 22-26. http://dx.doi.org/10.1016/j.partic.2014.04.007

[7] Iravani, S. (2011) Green Synthesis of Metal Nanoparticles Using Plants. Green Chemistry, 13, 2638-2650. http://dx.doi.org/10.1039/c1gc15386b

[8] Geraldes, A.N., Silva, D.F., Pino, E.S., Silva, J.C.M, Souza, R.F.B., Hammer, P., Spinacé, E.V., Neto, A.O., Linardi, M. and Santos, M.C. (2013) Ethanol Electro-Oxidation in an Alkaline Medium Using Pd/C, $\mathrm{Au} / \mathrm{C}$ and PdAu/C Electrocatalysts Prepared by Electron Beam Irradiation. Electrochimica Acta, 111, 455-465. http://dx.doi.org/10.1016/j.electacta.2013.08.021

[9] Geraldes, A.N., Silva, D.F., Silva, J.C.M., Souza, R.F.B., Spinacé, E.V., Neto, A.O., Linardi, M. and Santos, M.C. (2014) Glycerol Electrooxidation in Alkaline Medium Using $\mathrm{Pd} / \mathrm{C}, \mathrm{Au} / \mathrm{C}$ and $\mathrm{PdAu} / \mathrm{C}$ Electrocatalysts Prepared by Electron Beam Irradiation. Journal of Brazilian Chemical Society, 25, 831-840. http://dx.doi.org/10.5935/0103-5053.20140044

[10] Geraldes, A.N., Silva, D.F., Silva, L.G.A., Spinacé, E.V., Neto, A.O. and Santos, M.C. (2015) Binary and Ternary Palladium Based Electrocatalysts for Alkaline Direct Glycerol Fuel Cell. Journal of Power Sources, 293, 823-830. http://dx.doi.org/10.1016/j.jpowsour.2015.06.010

[11] Nune, S.K., Chanda, N., Shukla, R., Katti, K., Kulkarni, R.R., Thilakavathy, S., Mekapothula, S., Kannan, R. and Katti, K.V. (2009) Green Nanotechnology from Tea: Phytochemicals in Tea as Building Blocks for Production of Biocompatible Gold Nanoparticles. Journal of Materials Chemistry, 19, 2912-2920. http://dx.doi.org/10.1039/b822015h

[12] Choi, J., Park, S., Stojanović, Z., Han, H., Lee, J., Seok, H.K., Uskoković, D. and Lee, K.H. (2013) Facile Solvothermal Preparation of Monodisperse Gold Nanoparticles and Their Engineered Assembly of Ferritin-Gold Nanoclusters. Langmuir, 29, 15698-15703. http://dx.doi.org/10.1021/la403888f

[13] Kannan, R., Rahing, V., Cutler, C., Pandrapragada, R., Katti, K.K., Kattumuri, V., Robertson, J.D., Casteel, S.J., Jurisson, S., Smith, C., Boote, E. and Katti, K.V. (2006) Nanocompatible Chemistry toward Fabrication of Target-Specific Gold Nanoparticles. Journal of the American Chemical Society, 128, 11342-11343. http://dx.doi.org/10.1021/ja063280c

[14] Ashamalla, H., Rafla, S., Zaki, B., Nnaemeka, C.I. and Ross, P. (2002) Radioactive Gold Grain Implants in Recurrent and Locally Advanced Head-and-Neck Cancers. Brachytherapy, 1, 161-166. http://dx.doi.org/10.1016/S1538-4721(02)00054-5

[15] Alfonso, A.E., Hassan, A., Gardner, B., Stein, S., Patti, J., Solomon, N., McCarthy, J. and Steigman, J. (1978) Prevention of Hepatic Metastases by Intravenous Radioactive Gold. Cancer Research, 38, 2740-2744.

[16] Gonnelli, C., Cacioppo, F., Giordano, C., Capozzoli, L., Salvatici, M.C., Colzi, I., Bubbad, M.D., Ancillotti, C. and Ristori, S. (2015) Cucurbita pepo L. Extracts as a Versatile Hydrotropic Source for the Synthesis of Gold Nanoparticles with Different Shapes. Green Chemistry Letters and Reviews, 8, 39-47. http://dx.doi.org/10.1080/17518253.2015.1027288

[17] Mittal, A.K., Chisti, Y. and Banerjee, U.C. (2013) Synthesis of Metallic Nanoparticles Using Plant Extracts. Biotechnology Advances, 31, 346-356. http://dx.doi.org/10.1016/j.biotechadv.2013.01.003

[18] Luczaj, W. and Skrzydlewska, E. (2005) Antioxidative Properties of Black Tea. Preventive Medicine, 40, 910-918. http://dx.doi.org/10.1016/j.ypmed.2004.10.014

[19] Maeta, K., Nomura, W., Takatsume, Y., Izawa, S. and Inoue, Y. (2007) Green Tea Polyphenols Function as Prooxidants to Activate Oxidative-Stress-Responsive Transcription Factors in Yeasts. Applied and Environmental Microbiology, 73, 572-580. http://dx.doi.org/10.1128/AEM.01963-06

[20] Peterson, J., Dwyer, J., Bhagwat, S., Haytowitz, D., Holden, J., Eldridge, A.L., Beecher, G. and Aladesanmi, J. (2005) Major Flavonoids in Dry Tea. Journal of Food Composition and Analysis, 18, 487-501. http://dx.doi.org/10.1016/j.jfca.2004.05.006

[21] Sari, F., Turkmen, N., Polat, G. and Velioglu, Y.S. (2007) Total Polyphenol, Antioxidant and Antibacterial Activities of Black Mate Tea. Food Science and Technology Research, 13, 265-269. http://dx.doi.org/10.3136/fstr.13.265 
[22] Zhao, B.L. and Clin. J. (2006) The Health Effects of Tea Polyphenols and Their Antioxidant Mechanism. Journal of Clinical Biochemistry and Nutrition, 38, 59-68. http://dx.doi.org/10.3164/jcbn.38.59

[23] Sasak, W., Mankowski, T. and Chojnacki, T. (1976) Polypyrenols in Juniperus communis. FEBS Letters, 64, 55-58. http://dx.doi.org/10.1016/0014-5793(76)80247-5

[24] Nestor, A.R.V., Mendieta, V.S., López, M.A.C., Espinosa, R.M.G., López, M.A.C. and Alatorre, J.A.A. (2008) Solventless Synthesis and Optical Properties of Au and Ag Nanoparticles Using Camellia sinensis Extract. Materials Letters, 62, 3103-3105. http://dx.doi.org/10.1016/j.matlet.2008.01.138

[25] Ochacka, J.R., Asztemborska, M., Zook, D.R., Sybilska, D., Perez, G. and Ossicini, L. (1996) Enantiomers of Monoterpenic Hydrocarbons in Essential Oil from Juniperus communis. Phytochemistry, 44, 869-873. http://dx.doi.org/10.1016/S0031-9422(96)00587-0

[26] Elmastaş, M., Gülçin, L., Beydemir, S., Küfrevioğlu, O.I. and Aboul-Enein, H.Y. (2006) A Study on the In Vitro Antioxidant Activity of Juniper (Juniperus communis L.) Fruit Extracts. Analytical Letters, 39, 47-65. http://dx.doi.org/10.1080/00032710500423385

[27] Esquenazi, D., Wigg, M.D., Miranda, M.M.F.S., Rodrigues, H.M., Tostes, J.B.F., Rozental, S., da Silva, A.J.R. and Alviano, C.S. (2002) Antimicrobial and Antiviral Activities of Polyphenolics from Cocos nucifera Linn. (Palmae) Husk Fiber Extract. Research in Microbiology, 153, 647-652. http://dx.doi.org/10.1016/S0923-2508(02)01377-3

[28] Rinaldi, S., Silva, D.O., Bello, F., Alviano, C.S., Alviano, D.S., Matheus, M.E. and Fernandes, P.D. (2009) Characterization of the Antinociceptive and Anti-Inflammatory Activities from Cocos nucifera L. (Palmae). Journal of Ethnopharmacology, 122, 541-546. http://dx.doi.org/10.1016/j.jep.2009.01.024

[29] Paul, K., Bag, B.G. and Samanta, K. (2014) Green Coconut (Cocos nucifera Linn) Shell Extract Mediated Size Controlled Green Synthesis of Polyshaped Gold Nanoparticles and Its Application in Catalysis. Applied Nanoscience, 4, 769-775. http://dx.doi.org/10.1007/s13204-013-0261-6

[30] Elumalai, E.K., Kayalvizhi, K. and Silvan, S. (2014) Coconut Water Assisted Green Synthesis of Silver Nanoparticles. Journal of Pharmacy \& BioAllied Sciences, 6, 241-245. http://dx.doi.org/10.4103/0975-7406.142953

[31] Sujitha, M.V. and Kannan, S. (2013) Green Synthesis of Gold Nanoparticles Using Citrus Fruits (Citrus limon, Citrus reticulata and Citrus sinensis) Aqueous Extract and Its Characterization. Spectrochimica Acta Part A: Molecular and Biomolecular Spectroscopy, 102, 15-23. http://dx.doi.org/10.1016/j.saa.2012.09.042

[32] Rodero, M.S., Romero, J.M.F. and Hens, A.G. (2011) Photometric Determination of Thioglycolic Acid in Cosmetics by Using a Stopped-Flow Reverse Flow-Injection System and the Formation of Gold Nanoparticles. Microchemical Journal, 97, 243-248. http://dx.doi.org/10.1016/j.microc.2010.09.011

[33] Lee, A.F., Baddeley, C.J., Hardacre, C., Ormerod, R.M. and Lambert, R.M. (1995) Structural and Catalytic Properties of Novel Au/Pd Bimetallic Colloid Particles: EXAFS, XRD, and Acetylene Coupling. The Journal of Physical Chemistry, 99, 6096-6102. http://dx.doi.org/10.1021/j100016a053

[34] Mohanraj, V.J. and Chen, Y. (2006) Nanoparticles-A Review. Tropical Journal of Pharmaceutical Research, 5, 561573.

[35] Sonavanea, G., Tomodaa, K. and Makinoa, K., (2008) Biodistribution of Colloidal Gold Nanoparticles after Intravenous Administration: Effect of Particle Size. Colloids and Surfaces B: Biointerfaces, 66, 274-280. http://dx.doi.org/10.1016/j.colsurfb.2008.07.004

[36] Philip, D. (2010) Green Synthesis of Gold and Silver Nanoparticles Using Hibiscus rosa Sinensis. Physica E, 42, 1417-1424. http://dx.doi.org/10.1016/j.physe.2009.11.081 


\section{Submit or recommend next manuscript to SCIRP and we will provide best service for you:}

Accepting pre-submission inquiries through Email, Facebook, LinkedIn, Twitter, etc.

A wide selection of journals (inclusive of 9 subjects, more than 200 journals)

Providing 24-hour high-quality service

User-friendly online submission system

Fair and swift peer-review system

Efficient typesetting and proofreading procedure

Display of the result of downloads and visits, as well as the number of cited articles

Maximum dissemination of your research work

Submit your manuscript at: http://papersubmission.scirp.org/ 